\section{Long-term follow-up after endoscopic forceps biopsies for early stage duodenal carcinoid: case report and review of endoscopic treatments}

Duodenal carcinoids are neuroendocrine tumors that account for $2 \%$ to $13.6 \%$ of all gastrointestinal carcinoids, and no guidelines are available for their treatment. Small $(<2 \mathrm{~cm})$ nonperiampullary duodenal carcinoids without submucosal invasion have been termed early stage duodenal carcinoids (esDC) [1]; their clinical course appears favorable and endoscopic treatment would seem to be a feasible treatment option. We report on a female patient treated for an 8-mm polyp of the duodenal bulb, which was diagnosed as a carcinoid after forceps biopsies. At the subsequent check up, the patient was free of disease. At 11 years later, after 12 annual endoscopic examinations and periodic monitoring with abdominal computed tomography (CT) scan and octreotide scintigraphy, there was a recurrence of the neuroendocrine tumor, present in a biopsy of the duodenal scar. No further signs of carcinoid were found at the examination that followed shortly afterwards and so no further treatment was proposed. At 2 years after the recurrence, the patient is disease-free.

Treatment of duodenal carcinoids is a controversial issue; approaches include laser ablation, endoscopic and transduo- denal excision, duodenectomy, and pancreaticoduodenectomy. The morbidity rate for radical resection with lymphadenectomy appears unacceptable when weighed against the low risk of recurrence of esDC.

After a Medline search, we found reports on 31 cases of duodenal carcinoid treated by endoscopic procedures: 24 of these tumors were excised with disease-free margins, and seven (tumors smaller than $10 \mathrm{~mm}$ ) disappeared after forceps biopsies, and their depth of infiltration could not be determined at histopathology (Table 1]) [2-5]. These data suggest that complete endoscopic excision with tumor-free resection margins is the optimal treatment for nonperiampullary esDC without evidence of submucosal infiltration or lymph node metastases at intraluminal ultrasonography. The case reported here and some data in the literature suggest that for duodenal polyps that are smaller than $10 \mathrm{~mm}$, diagnosed as carcinoids after forceps biopsy, and without residual tumor at the second look, no further treatment is required but yearly endoscopic monitoring is advisable.

Endoscopy_UCTN_Code_CCL_1AB_2AZ_3AB
E. Urso ${ }^{1}$, S. Pucciarelli ${ }^{1}$, M. Cassaro ${ }^{2}$, M. Agostini ${ }^{1}$, D. Nitti ${ }^{1}$

1 Sezione di Clinica Chirurgica II, Dipartimento di Scienze Oncologiche e Chirurgiche, University of Padova, Padova, Italy

2 Servizio di Anatomia Patologica, Dipartimento di Scienze Oncologiche e Chirurgiche, University of Padova, Padova, Italy

\section{References}

1 Soga J. Early stage carcinoids of the gastrointestinal tract. Cancer 2005; 8: 1587-1595

2 Wengrower $D$, Fich A. Primary duodenal carcinoid. Am J Gastroenterol 1987; 82: 1069 1070

3 Hirakawa K, Iida M, Matsui Tet al. Endoscopic findings in carcinoid tumor of the duodenum. American J Gastroenterol 1991; 86: $603-605$

4 Yamamoto C, Aoyagi K, Suekane H et al. Carcinoid tumors of the duodenum: report of three cases treated by endoscopic resection. Endoscopy 1997; 29: $218-221$

5 Yoshikane H, Goto H, Niwa Y et al. Endoscopic resection of small duodenal carcinoid tumors with strip biopsy technique. Gastrointest Endosc 1998; 47: 66 - 470

Bibliography

DOI $10.1055 / \mathrm{s}-2007-966078$

Endoscopy 2007; 39: E128

(c) Georg Thieme Verlag KG Stuttgart · New York . ISSN 0013-726X

Corresponding author

S. Pucciarelli, MD

Dipartimento di Scienze Oncologiche e

Chirurgiche

Sezione di Clinica Chirurgica II

Policlinico, VI piano, Via Giustiniani, 2

35128 Padova, Italy

Fax: +39-049-651891

puc@unipd.it

Table 1 Reports of small $(<10 \mathrm{~mm})$ duodenal carcinoids $(\mathrm{n}=8)$ disappearing after forceps biopsies, with depth of infiltration unable to be determined at histopathological examination

\begin{tabular}{|lllll|}
\hline Author, year & Carcinoids, $\mathbf{n}$ & $\begin{array}{l}\text { Endoscopic } \\
\text { complications }\end{array}$ & $\begin{array}{l}\text { Median follow- } \\
\text { up (range), } \\
\text { months }\end{array}$ & $\begin{array}{l}\text { Local/distant } \\
\text { recurrence }\end{array}$ \\
$\begin{array}{l}\text { Wengrower \& } \\
\text { Fich, 1987 [2] }\end{array}$ & 2 & No & 24 & No/no \\
\hline $\begin{array}{l}\text { Hirakawa et } \\
\text { al., } 1991 \text { [3] }\end{array}$ & 2 & No & $5(1-9)$ & No/no \\
\hline $\begin{array}{l}\text { Yamamoto et } \\
\text { al., 1997 [4] }\end{array}$ & 1 & No & 148 & No/no \\
\hline $\begin{array}{l}\text { Yoshikane et } \\
\text { al., 1998 [5] }\end{array}$ & 2 & 1 & $16(6-27)$ & No/no \\
\hline $\begin{array}{l}\text { Present case } \\
\text { report, 2005 }\end{array}$ & 1 & No & 156 & Yes/no \\
\hline
\end{tabular}

* Two cases with no histological confirmation of tumor after strip biopsy. 